\title{
Severe Encephalopathy, Lactic Acidosis and Hyperammonaemia With FOLFIRI Plus Aflibercept After Two-stage Hepatectomy: A Case Report
}

\author{
YOSHIHIRO HARA, YUJI MIYAMOTO, YUKIHARU HIYOSHI, MASAAKI IWATSUKI, \\ YOSHIFUMI BABA, NAOYA YOSHIDA and HIDEO BABA \\ Department of Gastroenterological Surgery, Graduate School of Medical Sciences, \\ Kumamoto University, Kumamoto, Japan
}

\begin{abstract}
Background/Aim: Recent advances in chemotherapy have increased the possibility of conversion hepatectomy for patients with initially unresectable liver metastases. Although long-term chemotherapy and subsequent extensive hepatectomy are becoming more common, the toxicities of such chemotherapies are unclear. Patients and Methods: We present a case report of a patient with metastatic colorectal cancer who developed severe encephalopathy with lactic acidosis and hyperammonaemia caused by 5-fluorouracil-based chemotherapy. Administration of vitamin BI and continuous haemodiafiltration rapidly improved the patient's symptoms. Conclusion: Intensive treatment of metastatic colorectal cancer patients with 5fluorouracil can induce rare adverse events.
\end{abstract}

Colorectal cancer (CRC) is the fourth most common cause of death worldwide. Advances in chemotherapeutic options have markedly improved survival outcomes for patients with metastatic CRC. Indeed, recent clinical trials typically report median survival times of 30 months (1). Chemotherapy can increase the possibility of conversion hepatectomy for patients with initially unresectable liver tumours (2). For patients with CRC liver metastasis, two-stage hepatectomy after chemotherapy can now be performed safely, increasing the long-term survival. However, the toxicities of chemotherapy after two-stage hepatectomy have not been

This article is freely accessible online.

Correspondence to: Dr. Hideo Baba, Department of Gastroenterological Surgery, Graduate School of Medical Sciences, Kumamoto University, 1-1-1 Honjo, Kumamoto 860-8556, Japan. Tel: +81 963735212, Fax: +81963714378, e-mail: hdobaba@kumamotou.ac.jp

Key Words: Encephalopathy, lactic acidosis, hyperammonaemia, 5FU, metastatic colorectal cancer, hepatectomy. clarified. Here, we present a case of severe encephalopathy with lactic acidosis and hyperammonaemia caused by systemic chemotherapy for metastatic CRC.

\section{Case Report}

A 68-year-old female was diagnosed with advanced caecal cancer with multiple synchronous liver metastases in December 2016. Following primary tumour resection, the patient was treated with capecitabine and oxaliplatin plus bevacizumab. A computed tomography scan showed a good response to eight cycles of chemotherapy, and we therefore scheduled two-stage hepatectomy. We initially performed partial hepatectomy, radiofrequency ablation, and right portal vein embolisation for left lobe metastases. After liver regeneration, we performed right hepatectomy to remove the remaining liver metastases. Two months after surgery, we observed metastasis to the lung and intraperitoneal lymph nodes, and the patient was started on FOLFIRI (5-fluorouracil (5-FU) and irinotecan) plus aflibercept as second-line chemotherapy (Figure 1). However, she suffered a loss of consciousness during the 6th cycle of treatment and was taken to the emergency room. Blood test results revealed lactic acidosis (serum $\mathrm{pH} 7.3$, lactic acid concentration $18.7 \mathrm{mmol} / \mathrm{l})$ and hyperammonaemia $\left(\mathrm{NH}_{3}\right.$ $203 \mu \mathrm{g} / \mathrm{dl}$ ) (Table I). Loss of consciousness was attributed to encephalopathy, and the patient was admitted to the intensive care unit and treated with branched chain amino acids, sodium bicarbonate, and vitamin B1. Introduction of continuous haemodiafiltration (CHDF) led to an immediate improvement of symptoms. CHDF was stopped on the second day and the patient was discharged after 1 week of hospitalisation. Since hyperammonaemia and lactic acidosis have been reported as rare side effects of 5-FU therapy, we concluded that this patient's symptoms were caused by $5-\mathrm{FU}$. Chemotherapy was discontinued after discharge, but she remained on vitamin B1 and branched chain amino acid therapy with regular follow-up visits. She experienced no further instances of hyperammonaemia or lactic acidosis. 

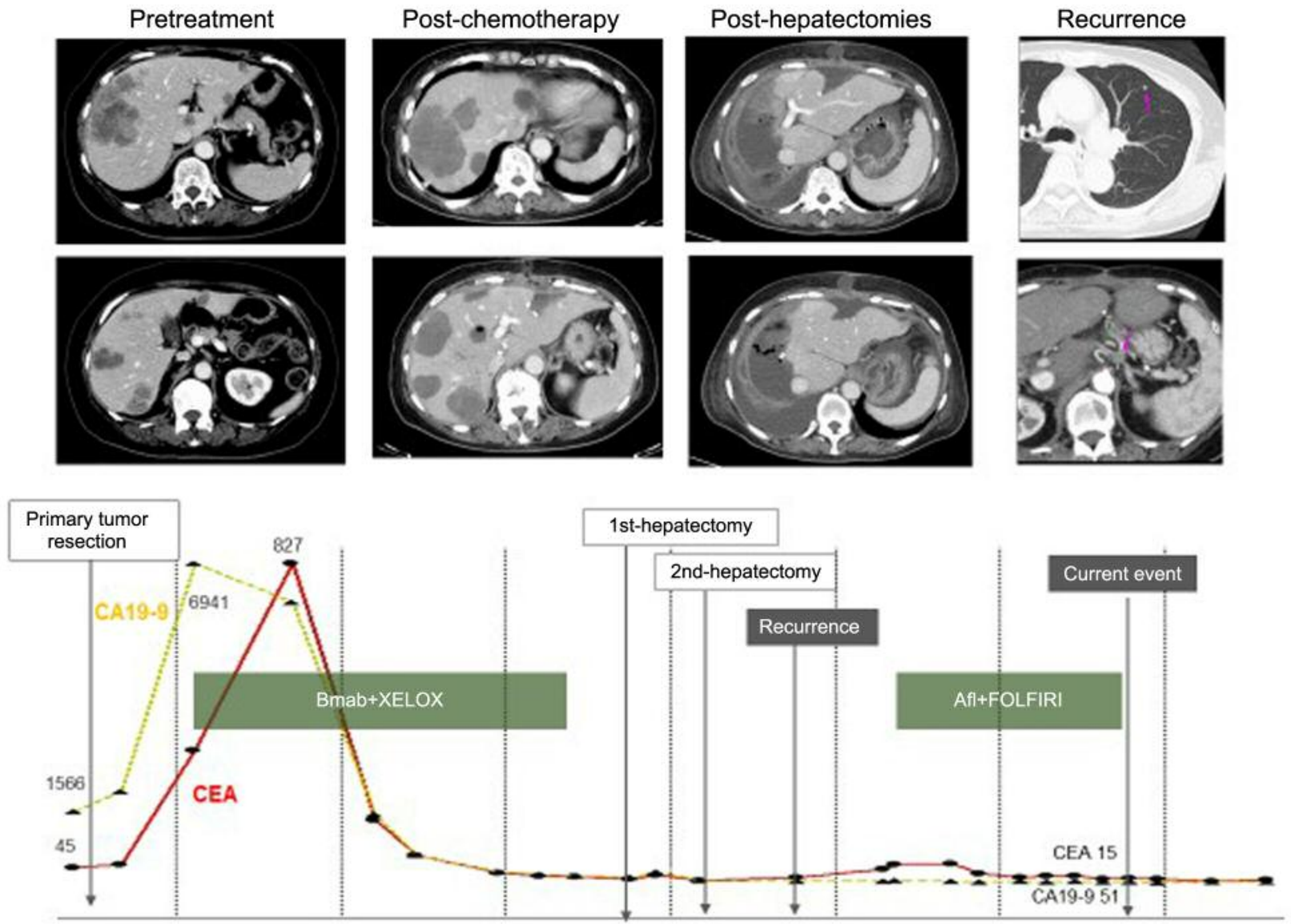

Figure 1. Detection of liver metastases by enhanced CT and clinical course.

\section{Discussion}

5-FU is an important component of first- and second-line chemotherapy regimens for metastatic CRC. The most common adverse events associated with 5-FU are gastrointestinal symptoms (nausea, vomiting, and diarrhoea) and bone marrow suppression (stomatitis, neutropenia, and thrombocytopaenia). There have been rare reports of lactic acidosis and hyperammonaemic encephalopathy due to administration of 5-FU (3-5). Although the underlying mechanisms of toxicity are unknown, three hypotheses have been proposed. The first suggests that hyperammonaemia occurs secondarily to ATP deficiency $(5,6)$. Ammonia is the final metabolite of 5-FU and is converted to urea through an adenosine triphosphate (ATP)-dependent cycle. However, the tricarboxylic acid cycle, which generates ATP, is inhibited by fluoroacetate, an intermediate catabolite of 5-FU. Thus, 5FU-induced ATP deficiency leads to inhibition of ammonia metabolism, resulting in hyperammonaemia $(5,6)$. Inhibition of the tricarboxylic acid cycle also induces the metabolism of pyruvate to lactate, resulting in lactic acidosis. The second hypothesis proposes that a deficiency in dihydropyrimidine dehydrogenase, which is responsible for the degradation of $85 \%$ of 5 -FU, leads to an increase in blood concentrations of 5-FU and its metabolite ammonia (7). In the third hypothesis, loss of appetite due to chemotherapy results in reduced thiamine uptake. 5-FU has also been reported to increase cellular thiamine metabolism. The resulting thiamine deficiency (beriberi) leads to lactic acidosis, Wernicke's encephalopathy, and peripheral neuropathy (4). In the patient described here, lactic acidosis and hyperammonaemia may have been caused by a combination of declining liver function after two-stage hepatectomy and decreased appetite and dehydration after chemotherapy. Although the patient could have been continued on 5-FU, we felt that the possibility of hyperammonaemia recurrence was too high. If she requires chemotherapy in the future, the treatment regimen will be changed to omit 5-FU. 
Table I. Blood analysis upon admission.

\begin{tabular}{|c|c|c|c|c|c|}
\hline Variable (unit) & Value & Variable (unit) & Value & Variable (unit) & Value \\
\hline $\mathrm{WBC}\left(\times 10^{3} / \mathrm{ml}\right)$ & 9.9 & $\mathrm{Ca}(\mathrm{mg} / \mathrm{dl})$ & 9.2 & $\mathrm{pH}$ & 7.143 \\
\hline $\mathrm{RBC}\left(\times 10^{6} / \mathrm{ml}\right)$ & 3.69 & BUN (mg/dl) & 10.7 & $\mathrm{pO}_{2}$ (Torr) & 93.2 \\
\hline $\mathrm{Hb}(\mathrm{g} / \mathrm{dl})$ & 9.5 & Crea $(\mathrm{mg} / \mathrm{dl})$ & 0.56 & $\mathrm{pCO}_{2}$ (Torr) & 15.4 \\
\hline Hct $(\%)$ & 32.7 & S-Glu (mg/dl) & 225 & $\mathrm{BE}(\mathrm{mEq} / \mathrm{l})$ & -21.8 \\
\hline $\operatorname{PLT}\left(\times 10^{3} / \mu \mathrm{l}\right)$ & 259 & T-Bil (mg/dl) & 2.2 & $\mathrm{Lac}(\mathrm{mg} / \mathrm{dl})$ & 16.13 \\
\hline Neut $(\%)$ & 39.3 & NH3 $(\mu \mathrm{g} / \mathrm{dl})$ & 204 & Alb (g/dl) & 3.4 \\
\hline Lymp (\%) & 51.9 & AST (U/l) & 109 & $\mathrm{Na}(\mathrm{mEq} / \mathrm{l})$ & 142 \\
\hline Mono (\%) & 6.4 & ALT (U/1) & 59 & CK (U/l) & 99 \\
\hline PT $(\%)$ & 86 & $\mathrm{LD}(\mathrm{U} / 1)$ & 293 & $\mathrm{CRP}(\mathrm{mg} / \mathrm{dl})$ & 0.73 \\
\hline APTT $(\%)$ & 80 & $\gamma$-GTP (U/1) & 152 & $\mathrm{~K}(\mathrm{mEq} / \mathrm{l})$ & 3.4 \\
\hline P-FDP $(\mu \mathrm{g} / \mathrm{ml})$ & 4.5 & $\operatorname{ALP}(\mathrm{U} / \mathrm{l})$ & 1245 & $\mathrm{Cl}(\mathrm{mEq} / \mathrm{l})$ & 105 \\
\hline D-dimer $(\mu \mathrm{g} / \mathrm{ml})$ & 1.7 & CHE (U/l) & 214 & Amy (U/l) & 69 \\
\hline $\mathrm{TP}(\mathrm{g} / \mathrm{dl})$ & 7.9 & & & & \\
\hline
\end{tabular}

$\gamma$-GTP1: $\gamma$-Glutamyltransferase; Alb: albumin; ALP: alkaline phosphatase; ALT: alanine aminotransferase; Amy: amylase; APTT: activated partial thromboplastin time; AST: aspartate aminotransferase; BE: base excess; BUN: blood urea nitrogen; Ca: calcium; CHE: cholinesterase; CK: creatine kinase; Cl: chloride; Crea: creatinine; CRP: c-reactive protein; D-dimer: d-dimer; Hb: hemoglobin; Hct: hematocrit; K: potassium; LAC: lactic acid; LD: lactate dehydrogenase; Lym: lymphocyte; Mono: monocyte; Na: sodium; Neu: neutrophil; $\mathrm{NH}_{3}$ : ammonia; $\mathrm{pCO}_{2}$ : partial pressure of carbon dioxide; P-FDP: plasma- fibrin-fibrinogen degradation product; $\mathrm{pH}$ : hydrogen ion exponent; $\mathrm{pO}_{2}$ : partial pressure of oxygen; PT: prothrombin time; S-Glu: serum glucose; T-Bil: total bilirubin; TP: total protein; WBC: white blood cell.

In conclusion, encephalopathy, lactic acidosis, and hyperammonaemia are rare adverse events associated with 5-FU. To our knowledge, there have been no other reports of these events occurring after two-stage hepatectomy. Caution should be exercised when introducing 5-FU-based chemotherapy to patients who have received long-term chemotherapy and undergone extensive liver resection.

\section{Acknowledgements}

The Authors would like to thank Anne M. O'Rourke, PhD, from Edanz Group (www.edanzediting.com/ac) for editing a draft of this manuscript.

\section{References}

1 Loupakis F, Cremolini C, Masi G, Lonardi S, Zagonel V, Salvatore L, Cortesi E, Tomasello G, Ronzoni M, Spadi R, Zaniboni A, Tonini G, Buonadonna A, Amoroso D, Chiara S, Carlomagno C, Boni C, Allegrini G, Boni L and Falcone A: Initial therapy with FOLFOXIRI and bevacizumab for metastatic colorectal cancer. N Engl J Med 371: 1609-1618, 2014.

2 Beppu T, Miyamoto Y, Sakamoto Y, Imai K, Nitta H, Hayashi $\mathrm{H}$, Chikamoto $\mathrm{A}$, Watanabe $\mathrm{M}$, Ishiko $\mathrm{T}$ and $\mathrm{Baba} \mathrm{H}$ : Chemotherapy and targeted therapy for patients with initially unresectable colorectal liver metastases, focusing on conversion hepatectomy and long-term survival. Ann Surg Oncol 21: S405413,2014
3 Valik D: Encephalopathy, lactic acidosis, hyperammonaemia and 5-fluorouracil toxicity. Br J Cancer 77: 1710-1712, 1998.

4 Rosen A, Van Kuilenburg A, Assmann B, Kuhlen M and Borkhardt A: Severe encephalopathy, lactic acidosis, vegetative instability and neuropathy with 5-fluorouracil treatment Pyrimidine degradation defect or beriberi? Case Rep Oncol 4: 371-376, 2011.

5 Yeh KH and Cheng AL: High-dose 5-fluorouracil infusional therapy is associated with hyperammonaemia, lactic acidosis and encephalopathy. Br J Cancer 75: 464-465, 1997.

6 Mitani S, Kadowaki S, Komori A, Sugiyama K, Narita Y, Taniguchi H, Ura T, Ando M, Sato Y, Yamaura H, Inaba Y, Ishihara $\mathrm{M}$, Tanaka $\mathrm{T}$, Tajika $\mathrm{M}$ and Muro $\mathrm{K}$ : Acute hyperammonemic encephalopathy after fluoropyrimidine-based chemotherapy: A case series and review of the literature. Medicine (Baltimore) 96: e6874, 2017.

7 Yi HJ, Hong KS, Moon N, Chung SS, Lee RA and Kim KH: Acute hyperammonemic encephalopathy after 5-fluorouracil based chemotherapy. Ann Surg Treat Res 90: 179-182, 2016.
Received November 11, 2018

Revised December 24, 2018

Accepted December 26, 2018 